\title{
Depletion of Primordial Germ Cells (PGCs) by X-irradiation to Extraembryonic Region of Chicken Embryos and Expression of Xenotransplanted Quail PGCs
}

\author{
Yusuke Atsumi ${ }^{1,2}$, Shigenobu Yazawa ${ }^{3}$, Fumitake Usui ${ }^{1,2}$, Yoshiaki Nakamura ${ }^{1,2,4}$, \\ Yasuhiro Yamamoto ${ }^{1,2,5}$, Takahiro Tagami ${ }^{4}$, Kohzy Hiramatsu ${ }^{1}$, \\ Hiroshi Kagami ${ }^{1}$ and Tamao Ono ${ }^{1}$ \\ ${ }^{1}$ Faculty of Agriculture, Shinshu University, 8304 Minamiminowa, Kamiina, Nagano 399-4598, Japan \\ ${ }^{2}$ Interdisciplinary Graduate School of Science and Technology, Shinshu University, \\ 8304 Minamiminowa, Kamiina, Nagano 399-4598, Japan \\ ${ }^{3}$ Department of Biophysics, Graduate School of Science, Kyoto University, \\ Kitashirakawa-Oiwake, Sakyo-ku, Kyoto 606-8502, Japan \\ ${ }^{4}$ National Institute of Livestock and Grassland Science, Tsukuba, Ibaraki 305-0901, Japan \\ ${ }^{5}$ Department of Integrated Genetics, National Institute of Genetics, Mishima, Shizuoka 411-8540, Japan
}

\begin{abstract}
The generation of germline chimeras by the transfer of primordial germ cells (PGCs) requires incorporation of the PGCs of the donor into the gonadal tissue of the recipient embryo. We investigated the utility of soft $\mathrm{x}$-irradiation with application of a lead $(12 \times 3 \times 0.25 \mathrm{~mm}, \sim 0.1 \mathrm{~g})$ shield to the embryo proper for the production of chicken-quail germline chimeras. Chicken embryos shielded during irradiation for $120 \mathrm{~s}(\sim 7.2 \mathrm{~Gy})$ at stages 13 to 17 showed a hatchability of 35\% (106/301), whereas the hatchability of unshielded embryos was $26 \%$ (27/105). The relative population of gonadal PGCs at stage 30 for embryos irradiated at stage 13 with or without shielding was 13 and 5\%, respectively, of the value for nonirradiated controls. Chicken embryos irradiated at stages 13 or 14 with or without shielding and transfused with quail embryonic blood containing PGCs each exhibited $\sim 130$ relative population of donor PGCs in the left gonad at stage 30 . Xenotransplanted hatchlings exhibited donor-derived PGCs as detected by Southern hybridization and PCR. Exposure of chicken embryos to $\sim 7.2$ Gy of $\mathrm{x}$-radiation at stage 13 with the application of a lead shield to the embryo proper is thus a feasible approach to depletion of endogenous germ cells and the production of chicken-quail germline chimeras.
\end{abstract}

Key words: chicken, chimera, primordial germ cell, quail, soft x-ray

J. Poult. Sci., 46: 136-143, 2009

\section{Introduction}

The first identifiable precursor cells for gametes are the primordial germ cells (PGCs). In avian embryos, PGCs are derived from epiblast cells that migrate from the central region of the area pellucida to the germinal crescent at its anterior border and then undergo multiplication (Eyal-Giladi et al., 1981; Ginsburg and Eyal-Giladi, 1987). After the formation of blood vessels in the germinal crescent, the PGCs enter these vessels and are transported by the embryonic circulation to the region of hindgut formation, where they leave the circulation and become associated with the mesentery and migrate into the gonadal

Received: November 25, 2008, Accepted: January 8, 2009

Correspondence: Dr. T. Ono, Faculty of Agriculture, Shinshu Univer-

sity, 8304 Minamiminowa, Kamiina, Nagano 399-4598, Japan.

(E-mail: tamaoon@shinshu-u.ac.jp) primordium (Swift, 1914; Mayer, 1964; Kuwana and Fujimoto, 1984; Tsunekawa et al., 2000).

The production of avian germline chimeras and donorderived offspring by the transfer of blastoderm cells or PGCs into host embryos has been described (Petitte et al., 1990; Kagami et al., 1997; Li et al., 2002; Kim et al., 2005; Kang et al., 2008; Nakamura et al., 2008). The generation of viable offspring from cryopreserved germline cells via germline chimeric chickens has also been demonstrated (Naito et al., 1992; Kino et al., 1997). Such procedures will likely play an important role in the preservation of foundation stocks and endangered species (Tajima et al., 1993; 2003; Kuwana et al., 2006). The production of germline chimeras requires incorporation of donor PGCs into the endogenous gonadal tissue of recipient embryos. The proportion of donor-derived gametes, however, is determined by the relative numbers of the 


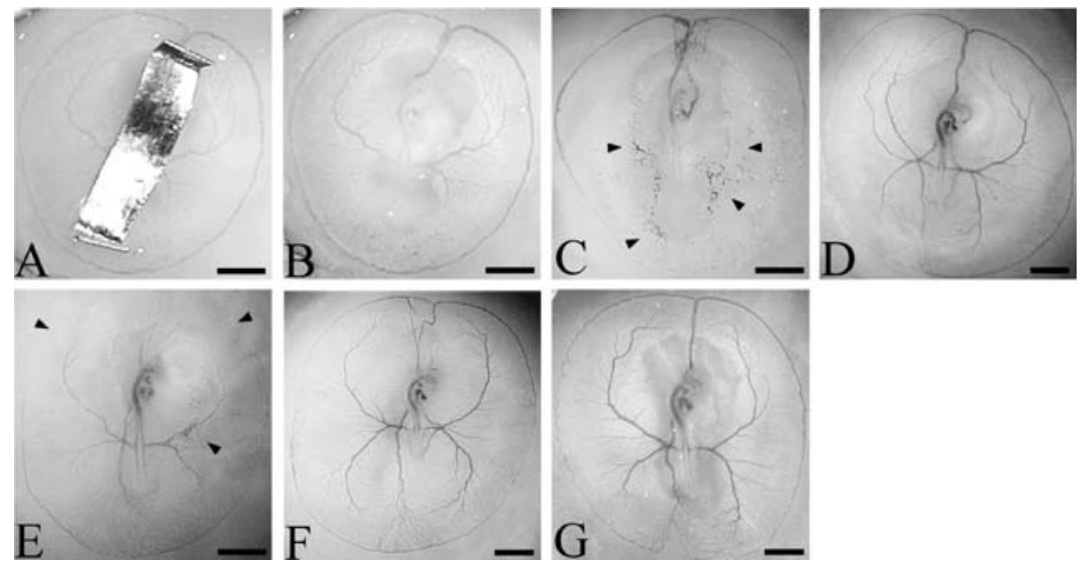

Fig. 1. Chicken embryos subjected to soft $x$-irradiation at stages 13 to 17 with (S) or without (U) shielding of the embryo proper. (A) Shielded embryo at stage 14 . A thin lead sheet $(12 \times 3 \times 0.25 \mathrm{~mm}, \sim 0.1 \mathrm{~g})$ was placed over the embryo proper to protect against irradiation. (B) Unshielded embryo at stage 14. (C) and (D) Shielded embryo $9 \mathrm{~h}$ after the irradiation showing disruption of the marginal vein (stage 15) and normal development (stage 17), respectively. (E) and (F) Unshielded embryo $9 \mathrm{~h}$ after the irradiation showing slight disruption of the marginal vein (stage 16-) and normal development (stage 17), respectively. (G) Nonirradiated embryo at stage 17. Arrowheads indicate disruption of the marginal vein. Bars, $3 \mathrm{~mm}$.

donor- and recipient-derived germ cells in the chimeric gonad. This proportion would be expected to be increased if the PGCs of the recipient could be removed, depleted, or inactivated. The ideal recipient, therefore, would be a healthy animal that has normal reproductive organs but which is sterile as a result of the absence only of the germ cells themselves (Li et al., 2001a). Exposure to soft (lowenergy) x-rays to blastoderm stage and stages 14-15 embryos has been shown to be effective in restricting the proliferation of quail and chicken PGCs (Li et al., 2001a; Lim et al., 2006; Nakamichi et al., 2006, Atsumi et al., 2008). We recently showed that exposure of chicken embryos to soft $\mathrm{x}$-rays reduced the number of PGCs in a dose-dependent manner (Atsumi et al., 2008). However, the irradiated embryos manifested delayed development and a reduced hatchability compared with nonirradiated controls. Alleviation of the radiation-induced loss of embryonic viability would be expected to result in a greater extent of endogenous PGC depletion and donor cell incorporation in recipient embryos.

We have now examined whether protection of the embryo proper with a lead shield during irradiation might restrict the proliferation of chicken PGCs with improved hatchability. We thus evaluated the utility of this approach for the production of germline chimeras from recipient chicken embryos.

\section{Materials and Methods}

\section{Animals}

The study was performed in accordance with the policies on animal care developed by the Animal Care and Management Committee of the Faculty of Agriculture, Shinshu University. Fertilized White Leghorn (Gallus domesticus) eggs were obtained from Goto Hatchery (Gifu, Japan).
Japanese quail (Coturnix japonica) with wild-type plumage were maintained in our laboratory and fertilized eggs were collected daily. The developmental stage of embryos was determined on the basis of the normal tables of Hamburger and Hamilton (1951).

\section{Embryo culture}

Fertilized chicken eggs were incubated for 48 to $64 \mathrm{~h}$ until they reached stages 13 to 17 . A hole was made in the blunt end of the egg with a needle to depressurize the air sac, a window with a diameter of $\sim 30 \mathrm{~mm}$ was opened in the narrow end, and a portion ( 4 to $8 \mathrm{ml}$ ) of albumen was removed. The window was sealed with cling film with the use of chicken thin albumen as a glue. The embryos were then incubated for $\sim 6.5$ days until they reached stage 30 or until hatching.

\section{Irradiation}

At stages 13 to 17 , a thin lead sheet $(12 \times 3 \times 0.25 \mathrm{~mm}$, $\sim 0.1 \mathrm{~g}$; Daiichiseiko, Osaka, Japan) was placed over the embryo proper to protect against irradiation (Fig. 1A), with the shielded embryos being designated S13 to S17, respectively. Some embryos were irradiated without a lead sheet (Fig. 1B), and these unshielded embryos were designated U13 to U17, respectively. Each egg was placed with the window upward on a turntable $(6 \mathrm{rpm})$ installed in the chamber of a soft x-ray apparatus (B-4; Softex, Tokyo, Japan). The embryo was set at a distance of $17 \mathrm{~cm}$ from the soft $\mathrm{x}$-ray source $(18 \mathrm{kV}$ power $)$. Shielded and unshielded embryos were irradiated for $120 \mathrm{~s}$. The radiation dosage was estimated to be $7.2 \mathrm{~Gy}$ on the basis of data supplied by Softex (Atsumi et al., 2008). A lead sheet at a thickness of $0.25 \mathrm{~mm}$ is impermeant to soft $\mathrm{x}$-ray in the present experimental condition according to the manufacturer's information. 


\section{Relative population of gonadal PGCs}

Embryos at stage 30 were removed from the yolk and fixed in Bouin's fluid. Gonadal tissue was serially sectioned at a thickness of $7 \mu \mathrm{m}$ and was processed for immunohistochemistry to detect gonadal PGCs with antibodies to the chicken vasa homolog $(\mathrm{CVH})$ protein (Nakamura et al., 2007) as described previously (Ono et al., 1998). The relative population of PGCs was determined by counting their number in 10 sections (every fourth serial section) in the middle region of the left gonad.

\section{Counting of circulating quail PGCs}

Blood $(2 \mu l)$ taken from the dorsal aorta of quail embryos at stages 13 to 14 was diluted with $18 \mu \mathrm{l}$ of Dulbecco's modified Eagle's medium (Gibco BRL, Grand Island, NY, USA) supplemented with 10\% fetal bovine serum (Nippon Bio-test Laboratories, Tokyo, Japan), and a well-dispersed sample was transferred to a hemocytometer for enumeration of PGCs (Atsumi et al., 2008). Quadruplicates were performed for enumerations.

\section{Transfer of quail PGCs to chicken embryos}

Chicken embryos at stages 13 to 14 were irradiated under the shielded or unshielded condition. Blood $(\sim 2$ $\mu l)$ was collected from quail embryos at stages 13 to 14 and transfused into the dorsal aorta of the irradiated chicken embryos with a fine glass pipette needle $(\mathrm{Li}$ et al., 2001b). Prior to transfusion, 2 to $3 \mu l$ of blood were removed from the recipient embryo to prevent the development of high blood pressure. Donor-derived PGCs in chimeric embryos at stage 30 were identified and counted by immunohistochemistry (as described above) with the QCR1 antibody, which recognizes a protein specific to quail PGCs (Aoyama et al., 1992; Ono et al., 1998).

\section{Molecular cloning}

Genomic DNA was extracted from the liver of a female quail hatchling as described (Tanaka et al., 2000). The DNA $(10 \mu \mathrm{g})$ was digested with the restriction endonuclease $B g l I I$, and the resulting fragments were fractionated by electrophoresis on a $1.5 \%$ agarose gel. The band corresponding to the $\sim 192$-bp satellite DNA fragment (Tanaka et al., 2000) was eluted from the gel and cloned into the plasmid pZErO-2 (Invitrogen, Carlsbad, CA, USA). The identity of the insert was confirmed by sequencing with M13 forward $(-20)$ and reverse primers and with the use of a BigDye Terminator v3.1 Cycle Sequencing Kit (Applied Biosystems, Tokyo, Japan) and a 3130xl Genetic Analyzer (Applied Biosystems).

\section{Southern blot hybridization}

A DNA probe (QS195) was prepared by digestion of the pZErO-2 plasmid containing the quail satellite DNA fragment with both HindIII and XhoI and was labeled with digoxigenin with the use of a random-priming DNA labeling kit (HighPrime; Roche Diagnostic, Mannheim, Germany). Quail or chicken genomic DNA was digested with $B g l \mathrm{II}$, and the resulting fragments were fractionated by electrophoresis on a $2 \%$ agarose gel, transferred to a Hybond-N+nylon membrane (Amersham Bioscience, Little Chalfont, UK), and subjected to hybridization with the QS195 probe. The membrane was thus incubated first for $60 \mathrm{~min}$ at $42^{\circ} \mathrm{C}$ with $5 \times$ saline sodium citrate (SSC, pH 4.5) containing $50 \%$ formamide, $1 \%$ SDS, yeast tRNA $(50 \mu \mathrm{g} / \mathrm{m} l)$, sonicated salmon sperm DNA $(100 \mu \mathrm{g} / \mathrm{ml})$, and heparin $(50 \mu \mathrm{g} / \mathrm{ml})$ and then overnight at $42^{\circ} \mathrm{C}$ with the same solution containing the QS195 probe $(100 \mathrm{ng} /$ $\mathrm{ml})$. It was then washed consecutively with $0.1 \%$ SDS in $2 \times \mathrm{SSC}$, with $0.1 \%$ SDS in $0.1 \times \mathrm{SSC}$, and with $0.3 \%$ Tween-20 in Tris-buffered saline (TBS-T). For the detection of hybridization signals, the membrane was incubated for $60 \mathrm{~min}$ at room temperature with alkaline phosphataseconjugated $\mathrm{Fab}$ fragments of sheep polyclonal antibodies to digoxigenin (1: 5000 dilution; Roche Diagnostic) in TBS-T containing 1.5\% Blocking Reagent (Roche Diagnostic). The membrane was then washed consecutively with TBS-T and with a solution containing $100 \mathrm{mM} \mathrm{NaCl}$, $100 \mathrm{mM}$ Tris- $\mathrm{HCl}$ ( $\mathrm{pH} 9.5$ ), and $50 \mathrm{mM} \mathrm{MgCl}_{2}$ before staining for $60 \mathrm{~min}$ at room temperature with nitroblue tetrazolium chloride and 5-bromo-4-chloro-3-indolyl phosphate (1: 50 dilution; Roche Diagnostic) in the latter solution. Excess stain was removed by incubation of the membrane with a solution containing $10 \mathrm{mM}$ Tris- $\mathrm{HCl}$ (pH 8.0) and $1 \mathrm{mM}$ EDTA.

\section{PCR analysis}

Genomic DNA was extracted with the use of a DNeasy Tissue Kit (Qiagen, Tokyo, Japan) from left gonadal tissue or blood of chicken hatchlings that had been transfused with quail PGCs as well as of control quail and chicken hatchlings. Quail genomic DNA was detected by the polymerase chain reaction (PCR) with the primers $5^{\prime}$ ACCGGTCTACGCAGCAAATC-3' (forward) and 5'CCCAATCACAAGCAGTGGTG-3' (reverse), which together were designated QS3 and were based on the sequence of the QS195 probe. Chicken genomic DNA was detected by PCR with the primers 5'-GAGTGTAGACAGTAGTGTATC-3' (forward) and 5'-CTCAGGGCACCATTTTCACTG-3' (reverse), which are targeted to the microsatellite locus LEI0171 (GenBank accession no. X 85538) on the $\mathrm{Z}$ chromosome (Schmid et al., 2000; Li et al., 2001c). PCR was performed in a final volume of 50 $\mu l$ for 30 cycles of denaturation at $94^{\circ} \mathrm{C}$ for $30 \mathrm{~s}$, annealing at $60^{\circ} \mathrm{C}$ for $30 \mathrm{~s}$, and extension at $72^{\circ} \mathrm{C}$ for $30 \mathrm{~s}$, with a preliminary denaturation at $94^{\circ} \mathrm{C}$ for $2 \mathrm{~min}$ and a final extension at $72^{\circ} \mathrm{C}$ for $5 \mathrm{~min}$. A portion of the PCR products $(10 \mu l)$ was subjected to electrophoresis on a $1.5 \%$ agarose gel, which was then stained with ethidium bromide.

\section{Statistical analysis}

Data were analyzed by Welch's $t$ test, the Mann-Whitney's $U$ test, or Spearman's correlation coefficient by rank test with the use of the Statcel add-in program for Microsoft Excel (Yanai, 2004) or by Fisher's exact probability test (http://aoki2.si.gunma-u.ac.jp/javascript/fisherexacttest. html; Yanai, 2004). A $P$ value of $<0.05$ was considered statistically significant. 


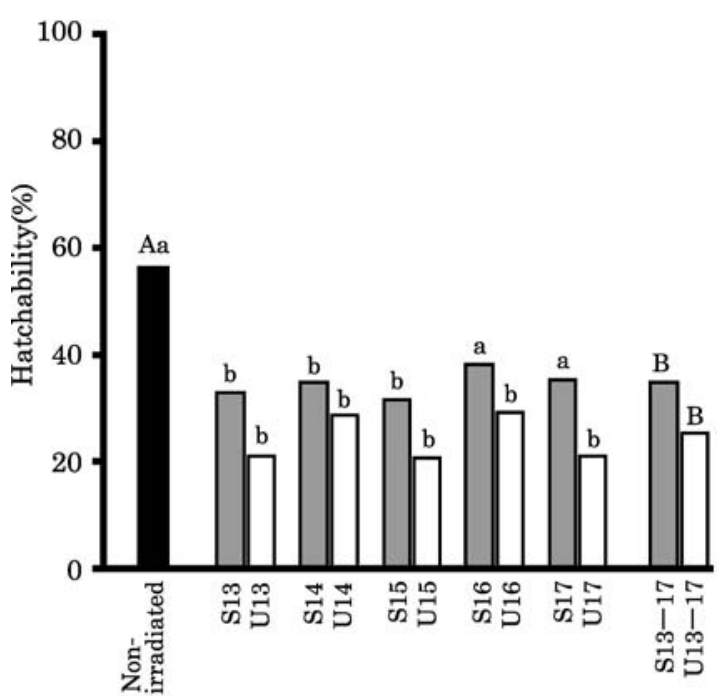

Fig. 2. Hatchability of $\mathbf{x}$-irradiated chicken embryos. Embryos were subjected to soft $\mathrm{x}$-irradiation at stages 13 to 17 with (S) or without (U) shielding of the embryo proper. The numbers of embryos examined were 36,71 , 71, 78 and 45 for S13 to S17 and 14, 31, 19, 27 and 14 for U13 to U17, respectively. The hatchability of nonirradiated $(n=30)$ embryos is shown for comparison. The significance of differences in hatchability between each shielded or unshielded group and the nonirradiated group is indicated by lowercase letters $(P<0.05$, Fisher's exact probability test), whereas that of differences between the combined shielded (S13-S17, $n=301$ ) or unshielded (U13U17, $n=105)$ groups and the nonirradiated group is indicated by uppercase letters $(P<0.05$, Fisher's exact probability test).

\section{Results}

\section{Embryonic development and hatchability}

Some of the chicken embryos exposed to soft x-rays with shielding of the embryo proper at stages 13 to 17 (S, Fig. 1A) showed disruption of the marginal vein during embryonic development, but the embryo proper appeared to be unaffected (Fig. 1C). In contrast, some embryos irradiated without shielding (U, Fig. 1B) showed slight disruption of the marginal vein (Fig. 1D). Other embryos showed normal development as the nonirradiated (windowed) controls (Figs. 1E, F, G).

Chicken embryos subjected to soft $\mathrm{x}$-irradiation at stages 13 to 17 were evaluated for hatchability (Fig. 2). The hatchability of S13 to S17 embryos was 33\% (12/36), $35 \%(25 / 71), 32 \%(23 / 71), 38 \%(30 / 78)$ and 36\% (16/ $45)$, respectively, whereas that of U13 to U17 embryos was $21 \%(3 / 14), 29 \%(9 / 31), 21 \%(4 / 19), 30 \%(8 / 27)$ and $21 \%(3 / 14)$, respectively. The hatchability of nonirradiated embryos was 57\% (17/30). The values for S16 and S17 embryos did not differ significantly from that of nonirradiated controls. There were no stage-specific differences in either treatment group (shielded or unshielded) or treatment-specific differences. The hatchability of the

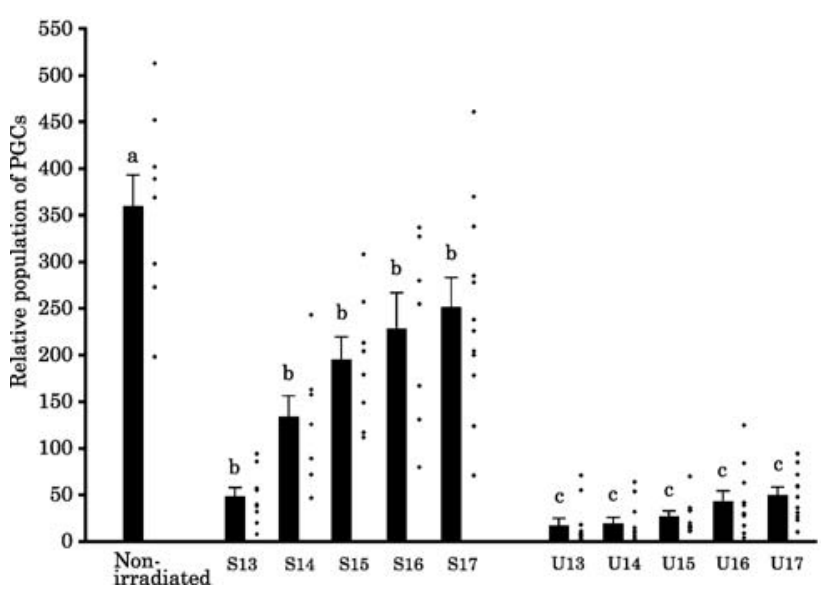

Fig. 3. Relative population of PGCs in the left gonad of $\mathbf{x}$-irradiated chicken embryos at stage 30. Embryos were exposed to soft $\mathrm{x}$-rays with (S) or without (U) shielding of the embryo proper at stages 13 to 17 , and the number of PGCs in the left gonad was determined by immunohistochemical analysis with antibodies to $\mathrm{CVH}$ at stage 30. The relative population of PGCs was determined by counting their number in 10 sections (every fourth serial section) in the middle region of the left gonad. Value for nonirradiated embryos is shown for comparison. The relative PGC population of each group of irradiated ( $S$ or U) embryos was significantly smaller than that of nonirradiated controls, as indicated by the lowercase letters $(P<0.05)$, and it increased in a stage-specific manner $(P<0.05$, Spearman's correlation coefficient by rank test). The number of PGCs in each unshielded group was also significantly lower that that in the corresponding shielded group $(P<0.05$, Mann-Whitney's $U$ test). Data are means $+\mathrm{SE}$ for 7 to 14 embryos, with each dot indicating the value for one embryo.

combined S13-S17 and U13-U17 groups was 35\% (106/ 301 ) and $26 \%(27 / 105)$, respectively, with both values being significantly lower than that for the nonirradiated group.

\section{Relative population of gonadal PGCs}

Gonadal PGCs in chicken embryos at stage 30 were visualized and enumerated by immunohistochemical analysis with antibodies to $\mathrm{CVH}$. The relative population of PGCs in the left gonad of nonirradiated controls was 355 \pm 32 (mean $\pm \mathrm{SE}, \quad n=9$ ). Those in S13 to S17 embryos were $48 \pm 9(n=9), 132 \pm 22(n=8), 192 \pm 24(n=8), 225$ $\pm 38(n=7)$ and $248 \pm 31(n=12)$, respectively, and those in $\mathrm{U} 13$ to $\mathrm{U} 17$ embryos were $18 \pm 7(n=11), 19 \pm 6(n=$ $11), 27 \pm 5(n=11), 43 \pm 11(n=11)$ and $50 \pm 8(n=11)$, respectively (Fig. 3). The numbers of PGCs expressed as a percentage of the value for nonirradiated controls were 13, 37, 54, 64 and 70\% for S13 to S17 embryos and 5, 5, 8, 12 and 14\% for U13 to U17 embryos, respectively. The relative population of PGCs of all the irradiated groups were significantly lower than that of nonirradiated controls. The relative population of PGCs also increased with 

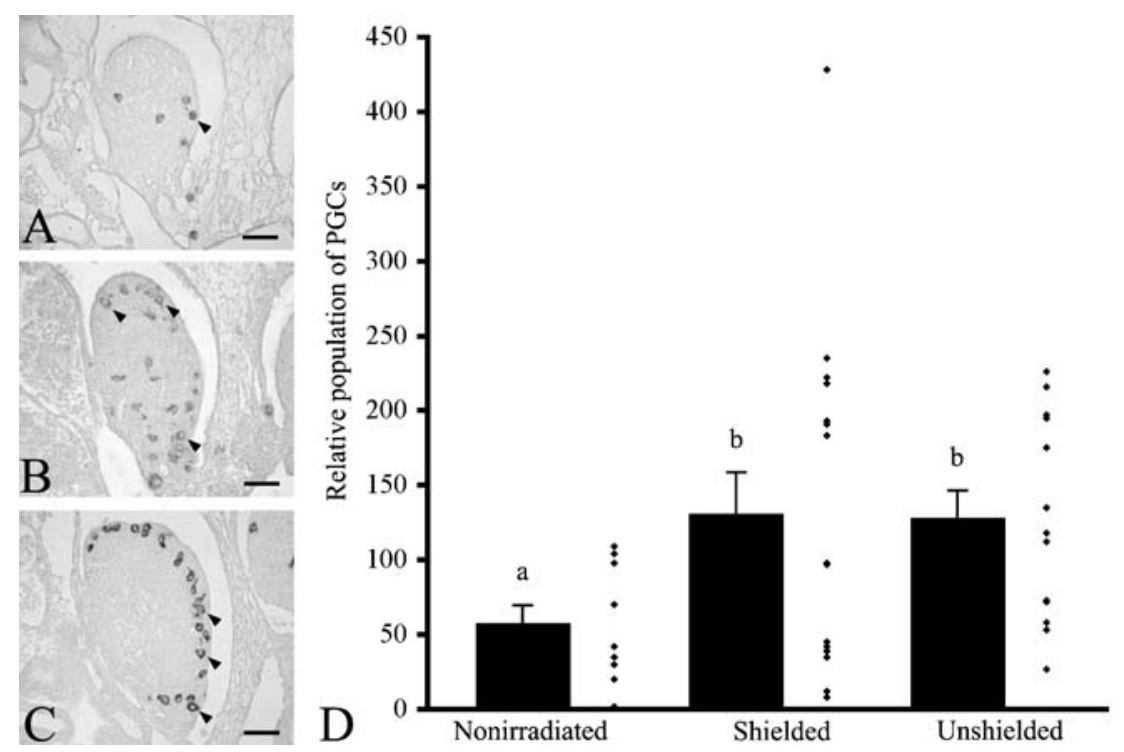

Fig. 4. Relative population of donor-derived (quail) PGCs in the left gonad of x-irradiated chicken embryos at stage 30. Chicken embryos were exposed to soft $x$-rays with or without shielding of the embryo proper at stages 13 to 14, transfused with quail embryonic blood containing PGCs, and incubated until stage 30, when the number of donor-derived PGCs in left gonadal tissue was determined by immunohistochemical analysis with the QCR1 antibody. The relative population of PGCs was determined by counting their number in 10 sections (every fourth serial section) in the middle region of the left gonad. Nonirradiated embryos were similarly transfused and incubated as controls. Representative immunohistochemical images for nonirradiated, shielded, and unshielded embryos are shown in (A), (B) and (C), respectively. Arrowheads indicate PGCs. Scale bars, $50 \mu \mathrm{m}$. The relative population of donor-derived PGCs in the shielded or unshielded groups was significantly greater than that in the nonirradiated group, as indicated by the lowercase letters $(P<0.05$, Welch's $t$ test) in (D); data are means + SE for 9 to 16 embryos, with each dot indicating the value for one embryo.

stage of irradiation in both shielded and unshielded groups and was lower in each unshielded group than in the corresponding shielded group.

\section{Transfer of quail PGCs to chicken embryos}

Chicken embryos were exposed to soft x-rays with or without shielding of the embryo proper at stages 13 to 14 and were then transfused with quail embryonic blood including PGCs. Quail embryos at stages 13 and 14 contained 127 $10(n=5)$ and $118 \pm 11(n=5) \mathrm{PGCs} / \mu \mathrm{l}$, respectively. Nonirradiated embryos were also similarly transfused as a control. The relative population of donorderived PGCs in left gonadal tissue of the recipient embryos at stage 30 was determined by immunohistochemical analysis with the QCR1 antibody (Fig. 4). The relative population of xenotransplanted quail PGCs was significantly greater in shielded $(130 \pm 29, n=16)$ or unshielded $(127 \pm$ $19, n=13)$ embryos than in nonirradiated controls $(57 \pm$ 13, $n=9$ ).

\section{Molecular cloning and Southern blot hybridization}

Genomic DNA extracted from quail liver was digested with $B g l \mathrm{II}$, the resulting fragments were fractionated by agarose gel electrophoresis, and the $\sim 192$-bp satellite DNA fragment described previously (Tanaka et al., 2000) was isolated from the gel, cloned into the plasmid pZErO2, and sequenced (Fig. 5A). The insert size of the clone was $195 \mathrm{bp}$ and the sequence was $43 \%$ identical to that of the previously described 192-bp fragment (Tanaka et al., 2000). A probe (QS195) was generated from the insert and was used for Southern blot analysis of chicken and quail genomic DNA (Fig. 5B). Intense hybridization signals were observed with quail DNA but not with chicken DNA, demonstrating the sequence specificity of the satellite DNA fragment. Specific hybridization signals were obtained with DNA from gonadal tissue (but not with that from blood) of chimeric hatchlings (Fig. 5B).

\section{PCR analysis}

Genomic DNA extracted from chicken or quail blood was subjected to PCR analysis with a primer set (QS3) targeted to the 195-bp fragment of quail satellite DNA (Fig. 5A). Whereas genomic DNA of chicken did not yield specific PCR products, that of quail yielded two major products of $155 \mathrm{bp}$ and $\sim 1.5$ to $2.0 \mathrm{kbp}$ (Fig. 6A). These products were detected at a quail DNA concentration in the PCR mixture of $\geq 0.1 \mathrm{pg} / \mu \mathrm{l}$.

We next performed PCR with the QS3 primer set and with genomic DNA (10 ng) extracted from gonadal tissue or blood of chicken hatchlings that had been irradiated (shielded or unshielded) as embryos and transfused with quail PGCs. Specific PCR products were obtained with DNA from gonadal tissue (but not with that from blood) of nonirradiated (6/8), shielded $(9 / 10)$ or unshielded (7/ 8) chimeric embryos (Fig. 6B). PCR analysis with primers 

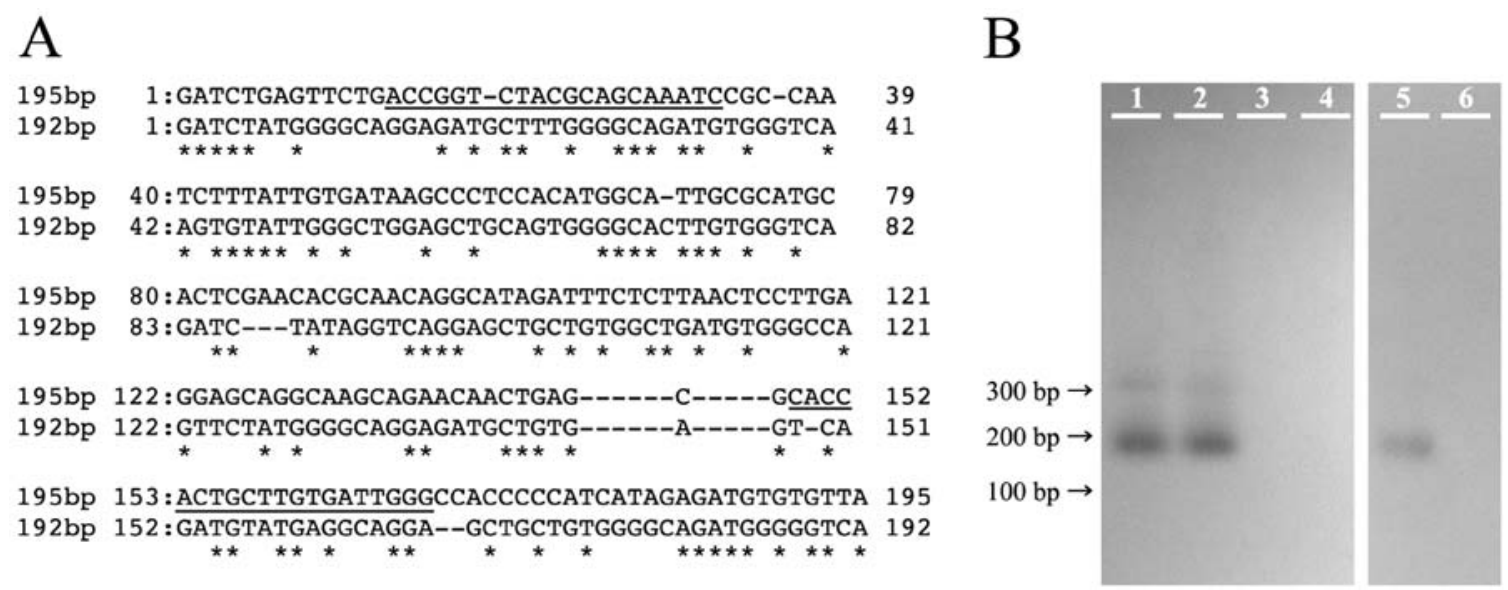

Fig. 5. Characterization of a satellite DNA clone of quail. (A) Genomic DNA extracted from quail liver was digested with $B g l \mathrm{II}$, the resulting fragments were fractionated by agarose gel electrophoresis, and the $\sim 192$-bp satellite DNA fragment described previously (Tanaka et al., 2000) was isolated from the gel, cloned, and sequenced. The 195-bp sequence is shown together with that of the previously described 192-bp sequence. Asterisks indicate identical residues, and underlined sequences correspond to primers for PCR analysis (Fig. 6). (B) Southern blot hybridization of $B g l$ II-digested genomic DNA (5 $\mu$ g) with a probe corresponding to the 195-bp DNA fragment isolated in (A). Lanes 1 and 2: liver of male and female quail, respectively. Lanes 3 and 4: liver of male and female chicken, respectively. Lanes 5 and 6: gonadal tissue and blood of a shielded chimeric chicken, respectively.

targeted to the LEI0171 microsatellite locus of chicken genomic DNA yielded specific PCR products with both blood and gonadal tissue samples of all chimeric embryos (Fig. 6C).

\section{Discussion}

Some of the chicken embryos exposed to soft x-rays showed delayed development and disruption of the marginal vein, but the embryo proper appeared to be unaffected. Degree of damage seemed to be higher in shielded embryos compared with unshielded embryos with unknown reason. Although the hatchability of shielded embryos was greater than that of unshielded embryos, the difference was not statistically significant $(P=0.09$, Fisher's exact probability test).

Exposure of chicken embryos to soft x-rays resulted in depletion of endogenous PGCs. Irradiation of shielded embryos at stage 13 induced a marked decrease in the number of PGCs detected at stage 30 shown as the relative population, whereas that at stages 15 to 17 appeared less effective, likely because some PGCs had already migrated to the lateral plate mesoderm (presumptive gonadal ridge) in the embryo proper. Irradiation of unshielded embryos appeared more effective than that of shielded embryos in depleting endogenous PGCs, although this increased efficacy seemed to be compromised by a reduced hatchability.

The introduction of donor PGCs into recipient embryos results in competition between the proliferation of donor and recipient PGCs in the host gonad (Nakamichi et al., 2006; Atsumi et al., 2008; Nakamura et al., 2008). In the present study quail embryos at stages 13 to 14 contained $118-127 \mathrm{PGCs} / \mu l$ in blood and the concentration was corresponded to the previous observation (Li et al., 2001 b); 250 PGCs were xenotransplanted to chicken embryos. Total number of donor-derived PGCs was unknown, although, $\sim 130$ donor-derived PGCs shown as the relative population were observed in the left gonad of both shielded and unshielded embryos at stage 30 . The numbers of endogenous PGCs in S13 and U13 embryos at stage 30 were 13 and $5 \%$, respectively, of that in nonirradiated controls; this depletion of endogenous PGCs by irradiation possibly resulted in a more than twofold increase in the number of donor-derived PGCs in both shielded and unshielded embryos relative to that in nonirradiated embryos. The numbers of donor-derived PGCs in shielded and unshielded embryos were similar, but the numbers of endogenous PGCs were not counted in these embryos. We previously showed that transferred quail PGCs constituted $16.5 \%$ of total PGCs in the left gonad of chicken embryos at stage 29 that had been transfused with quail blood at stages 14 to 16 (Ono et al., 1998). It remains to be determined, however, whether quail or chicken PGCs are capable of proliferating and functioning after interspecies transfer. Kang et al. (2008) recently transferred pheasant gonadal PGCs to chicken embryos at stage 17 and showed that mating of a resulting male chimera with a female pheasant gave rise to pheasant progeny.

Among various PCR primers specific for quail DNA, we selected a primer set targeted to a $B g l \mathrm{II}$ fragment of satellite DNA in order to distinguish quail from chicken DNA. We cloned a 195-bp DNA fragment that was 43\% identical to a 192-bp fragment described by Tanaka et al. (2000), with the sequence difference likely being attribut- 
A

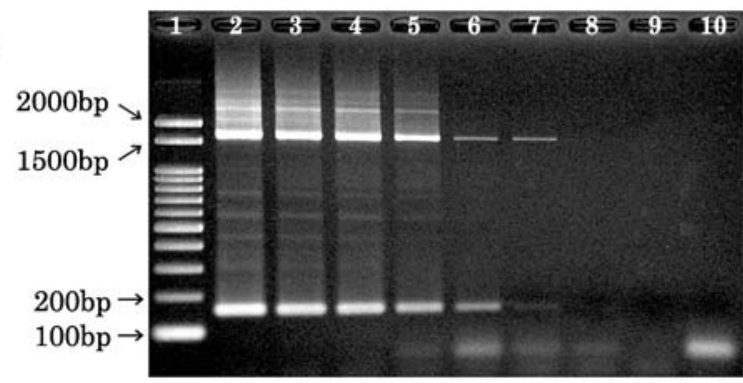

B

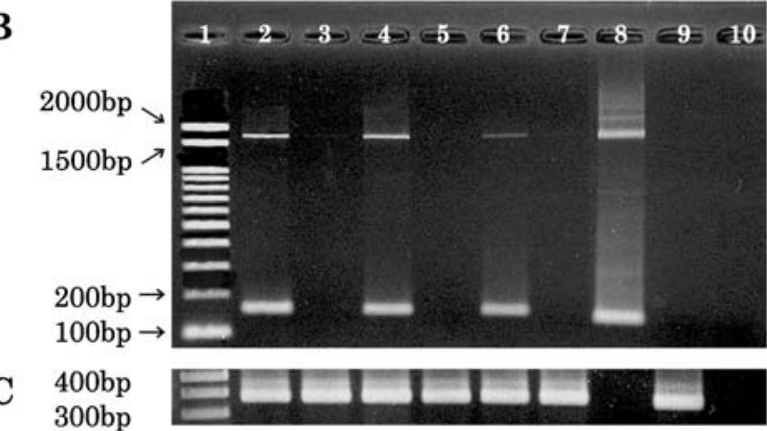

Fig. 6. Detection of germline chimerism in chicken hatchlings by PCR. (A) PCR analysis with the QS3 primer set. Lane 1: 100-bp ladder of molecular size markers. Lanes 2 to 8: genomic DNA from quail blood at concentrations of 10,000,1000,100,10,1, 0.1 and $0.01 \mathrm{pg} / \mu \mathrm{el}$, respectively. Lane 9: genomic DNA from chicken blood $(10 \mathrm{ng} / \mu l)$. Lane 10: negative control (sterile water). (B) PCR analysis with the QS3 primer set. Lane 1: 100 bp-ladder of molecular size markers. Lanes 2 and 3: genomic DNA $(10 \mathrm{ng} / \mu l)$ from gonadal tissue and blood, respectively, of a nonirradiated chimera. Lanes 4 and 5: genomic DNA $(10 \mathrm{ng} / \mu l)$ from gonadal tissue and blood, respectively, of a shielded chimera. Lanes 6 and 7: genomic DNA $(10 \mathrm{ng} / \mu \mathrm{l})$ from gonadal tissue and blood, respectively, of an unshielded chimera. Lane 8: genomic DNA $(10 \mathrm{ng} / \mu \mathrm{l})$ from quail gonadal tissue. Lane 9: genomic DNA $(10 \mathrm{ng} / \mu \mathrm{\mu l})$ from gonadal tissue of a nonchimeric chicken. Lane 10: negative control (sterile water). (C) PCR analysis with the LEI0171 primer set. Samples are as in (B).

able to the independent clone. Our attempts to amplify quail DNA with primer sets designed on the basis of the 192-bp sequence described by Tanaka et al. (2000) failed to yield specific PCR products. Several species-specific primer sets have previously been used in chimera and hybrid analysis (Li et al., 2001c; Naito et al., 2004; Naito et al., 2007a; 2007b; Takagi et al., 2007; Choi et al., 2008; Kang et al., 2008; Minematsu et al., 2008). The QS3 primer set designed in the present study yielded two major quail-specific DNA products of 155 bp and $\sim 1.5$ to 2.0 kbp and was able to amplify quail donor-derived DNA from the gonadal tissue of chimeric chicken hatchlings. A quail DNA concentration of at least $0.1 \mathrm{pg} / \mu \mathrm{l}$ in the PCR mixture was required for detection of the quail-specific products. It might be possible to lower this limiting concentration of quail DNA by the development of a more sensitive PCR protocol or a more efficient primer set.

In conclusion, we have shown that exposure of chicken embryos at stages 13 or 14 to soft $\mathrm{x}$-rays with shielding of the embryo proper is a feasible approach to depletion of endogenous germ cells and the generation of germline chimeras. Molecular analysis also revealed that the QS195 probe and QS3 primer set are potentially useful tools for the specific detection of quail DNA by Southern hybridization and PCR, respectively.

\section{Acknowledgments}

Part of this study was presented at the XXIII World's Poultry Congress in Brisbane, Australia (2008), with travel support to Y.A. from the Japan Poultry Science Association. This study was supported in part by Grantsin-Aid for Scientific Research from the Japan Society for the Promotion of Science to T.O.

\section{References}

Aoyama H, Asamoto K, Nojyo Y and Kinutani M. Monoclonal antibodies specific to quail embryo tissues: their epitopes in the developing quail embryo and their application to identification of quail cells in quail-chick chimeras. Journal of Histochemistry and Cytochemistry, 40: 1769-1777. 1992.

Atsumi Y, Tagami T, Kagami $\mathrm{H}$ and Ono T. Restriction of germline proliferation by soft $\mathrm{X}$-ray irradiation of chicken embryos and its application to chimera production. Journal of Poultry Science, 45: 292-297. 2008.

Choi JW, Lee EY, Shin JH, Zheng Y, Cho BW, Kim J-K, Kim $\mathrm{H}$ and Han JY. Identification of breed-specific DNA polymorphisms for a simple and unambiguous screening system in germline chimeric chickens. Journal of Experimental Zoology. Part A, Ecological Genetics and Physiology, 307A: 241-248. 2008.

Eyal-Giladi H, Ginsburg M and Farbarov A. Avian primordial germ cells are of epiblastic origin. Journal of Embryology and Experimental Morphology. 65: 139-147. 1981.

Ginsburg $\mathbf{M}$ and Eyal-Giladi H. Primordial germ cells of the young chick blastoderm originate from the central zone of the area pellucida irrespective of the embryo-forming process. Development, 101: 209-219. 1987.

Hamburger V and Hamilton HL. A series of normal stages in the development of chick embryos. Journal of Morphology, 88: 49-92. 1951.

Kagami H, Tagami H, Matsubara Y, Harumi T, Hanada H, Maruyama K, Sakurai M, Kuwana T and Naito M. The developmental origin of primordial germ cells and the transmission of the donor-derived gametes in mixed-sex germline chimeras to the offspring in the chicken. Molecular Reproduction and Development, 48: 501-510. 1997.

Kang SJ, Choi JW, Kim SY, Park KJ, Kim TM, Lee YM, Kim H, Lim JM and Han JY. Reproduction of wild birds via interspecies germ cell transplantation. Biology of Reproduction, 79: 931-937. 2008.

Kim MA, Park TS, Kim JN, Park HJ, Lee YM, Ono T, Lim JM and Han JY. Production of quail (Coturnix japonica) germline chimeras by transfer of gonadal primordial germ cells into recipient embryos. Theriogenology, 63: 774-782. 2005. 
Kino K, Pain B, Leibo SP, Cochran M, Clark ME and Etches RJ. Production of chicken chimeras from injection of frozen-thawed blastodermal cells. Poultry Science, 76: 753760. 1997.

Kuwana T, and Fujimoto T. Locomotion and scanning electron microscopic observations of primordial germ cells from the embryonic chick blood in vitro. Anatomical Record, 209: 337-343. 1984.

Kuwana T, Kawashima T, Naito M, Yamashita H, Matsuzaki M and Takano T. Conservation of a threatened indigenous fowl (Kureko Dori) using the germline chimeras transplanted from primordial germ cells. Journal Poultry Science, 43: 60-66. 2006.

Li HC, Kagami H, Matsui K and Ono T. Restriction of proliferation of primordial germ cells by the irradiation of Japanese quail embryos with soft X-rays. Comparative Biochemistry and Physiology. Part A: Molecular and Integrative Physiology, 130: 133-140. 2001a.

Li HC, Matsui K and Ono T. Population of circulating primordial germ cells in early Japanese quail embryos. Journal of Poultry Science, 38: 175-180. 2001b.

Li HC, Zhao L, Kagami H, Matsui K and Ono T. Identification of transferred chicken germ cells in quail gonad and semen by amplification of chicken-specific PCR products. Journal of Poultry Science, 38: 308-316. 2001c.

Li ZD, Deng H, Liu CH, Song YH, Sha J, Wang N and Wei H. Production of duck-chicken chimeras by transferring early blastodermal cells. Poultry Science, 81: 1360-1364. 2002.

Lim JM, Kwon HM, Kim DK, Kim JN, Park TS, Ono T and Han JY. Selective decrease of chick embryonic primordial germ cells in vivo and in vitro by soft X-ray irradiation. Animal Reproduction Science, 95: 67-74. 2006.

Mayer DB. The migration of primordial germ cells in the chick embryo. Developmental Biology, 10: 154-190. 1964.

Minematsu T, Harumi T and Naito M. Quantitative genotyping by amplifying the polymorphic sequences of Pre-Melanosomal Protein (PMEL17) gene using real-time polymerase chain reaction in chickens. British Poultry Science, 49: 542-549. 2008.

Naito M, Nirasawa K and Oishi T. Preservation of quail blastoderm cells in liquid nitrogen. British Poultry Science, 33: 449-453. 1992.

Naito M, Sano T, Harumi Y, Matsubara Y and Kuwana T. Migration of primordial germ cells isolated from embryonic blood into the gonads after transfer to stage $\mathrm{X}$ blastoderms and detection of germline chimaerism by PCR. British Poultry Science, 45: 762-768. 2004.

Naito M, Harumi T, Minematsu T, Tajima A and Kuwana T. Effect of soft X-ray irradiation on the migratory ability of primordial germ cells in chickens. British Poultry Science, 48: 121-126. 2007a.

Naito M, Minematsu T, Hatumi T and Kuwana T. Testicular and ovarian gonocytes from 20-day incubated chicken embryos contribute to germline lineage after transfer into bloodstream of recipient embryos. Reproduction, 134: 577-584. 2007b.

Nakamichi H, Sano A, Harumi T, Matsubara Y, Tajima A,
Kosugiyama M and Naito M. Effects of soft X-ray irradiation to stage $\mathrm{X}$ blastoderm on restriction of proliferation of primordial germ cells in early chicken embryos. Journal of Poultry Science, 43: 394-400. 2006.

Nakamura Y, Yamamoto Y, Usui F, Mushika T, Ono T, Setioko AR, Takeda K, Nirasawa K, Kagami $\mathrm{H}$ and Tagami $\mathrm{T}$. Migration and proliferation of primordial germ cells in the early chicken embryo. Poultry Science, 86: 2182-2193. 2007.

Nakamura Y, Yamamoto Y, Usui F, Atsumi Y, Ito Y, Ono T, Takeda K, Nirasawa K, Kagami $\mathrm{H}$ and Tagami T. Increased proportion of donor primordial germ cells in chimeric gonads by sterilization of recipient embryos using busulfan sustained-release emulsion in chickens. Reproduction, Fertility and Development, 20: 900-907. 2008.

Ono T, Yokoi R, Maeda S, Nishida T and Aoyama H. Settlement of quail primordial germ cells in chicken gonads. Animal Science and Technology (Jpn), 69: 546-555. 1998.

Petitte JN, Clark ME, Liu G, Verrinder Gibbins AM and Etches RJ. Production of somatic and germline chimeras in the chicken by transfer of early blastodermal cells. Development, 108: 185-189. 1990.

Schmid M, Nanda I, Guttenbach M, Steinlein C, Hoehn M, Schartl M, Haaf T, Weigend S, Fries R, Buerstedde JM, Wimmers K, Burt DW, Smith J, A' Hara S, Law A, Griffin DK, Bumstead N, Kaufman J, Thomson PA, Burke T, Groenen MA, Crooijmans RP, Vignal A, Fillon V, Morisson M, Pitel F, Tixier-Boichard M, Ladjali-Mohammedi K, Hillel J, Mäki-Tanila A, Cheng HH, Delany ME, Burnside J and Mizuno S. First report on chicken genes and chromosomes 2000. Cytogenetics and Cell Genetics, 90: 169-218. 2000.

Swift $\mathrm{CH}$. Origin and early history of the primordial germ cells in the chicken. The American Journal of Anatomy, 15: 483516. 1914.

Tajima A, Barbato GF, Kuwana T and Hammerstedt RH. Conservation of a genetically selected broiler line (42L) using cryopreserved circulating primordial germ cells (PGCs) isolated by filtration method. Journal of Poultry Science, 40: 53-61. 2003.

Tajima A, Naito M, Yasuda Y and Kuwana T. Production of germ line chimera by transfer of primordial germ cells in the domestic chicken (Gallus domesticus). Theriogenology, 40: 509-519. 1993.

Takagi S, Ono T, Tsukada A, Atsumi Y, Mizushima S, Saito N and Shimada K. Z-chromosome specific primers for chickenquail hybrid blastoderm. Journal of Poultry Science, 44: 209212. 2007.

Tanaka K, Suzuki T, Nojiri T, Yamagata T, Namikawa T and Matsuda Y. Characterization and chromosomal distribution of a novel satellite DNA sequence of Japanese quail (Coturnix coturnix japonica). Journal of Heredity, 91: 412-415. 2000.

Tsunekawa N, Naito M, Sakai Y, Nishida T and Noce T. Isolation of chicken vasa homolog gene and tracing the origin of primordial germ cells. Development, 127: 27412750. 2000.

Yanai H. Statcel-The Useful Addin Forms on Excel. 2nd ed. OMS Publications. Tokorozawa, Japan. 2004. 